\title{
The Effect of COVID-19 on the Atmospheric Parameters Over the Indian Subcontinent
}

\section{Ramprasad $\dagger$}

School of Civil Engineering, SASTRA Deemed to be University, Thanjavur, Tamil Nadu, India

$†$ Corresponding author: C. Ramprasad; ramprasad@ civil.sastra.edu

Nat. Env. \& Poll. Tech. Website: www.neptjournal.com

Received: 05-07-2020

Revised: $10-09-2020$

Accepted: 16-09-2020

Key Words:

Aerosol index

Carbon monoxide

COVID 19

Nitrogen dioxide

Spatio-temporal variation

\begin{abstract}
In the present study, the atmospheric concentrations of various pollutants over the Indian subcontinent before the COVID-19 (during 2019) and during COVID-19 phases (2020) were studied. The COVID-19 has created a negative impact on the country's economy but has positivity over the atmospheric resources. The levels of carbon monoxide (CO), nitrogen dioxide $\left(\mathrm{NO}_{2}\right)$, and UV aerosol index were assessed using satellite images for the two different phases. The obtained results can be interpreted and can be substantiated with the lockdown effect due to the COVID -19 pandemic. The pollutants are mostly emitted from anthropogenic sources like vehicular emissions, industrial emissions, power plants, construction works, commercial and institutional places. It was evident that the levels of carbon monoxide, nitrous dioxide and aerosols levels have drastically decreased during the lockdown period. Hence, it can be concluded that COVID-19 has cleaned the atmospheric pollution as well as climate change scenario and nature on its own.
\end{abstract}

\section{INTRODUCTION}

The Corona diseases 2019 (COVID-19) has become a global pandemic and was the greatest threat to more than 200 countries and infected more than 3 million people globally (WHO 2020). The United Nations Department of Economic and Social Affairs (UNDESA) has predicted that the COVID-19 pandemic has troubled the global economy and it could shrink by $1 \%$ in 2020 . Many countries have adopted the control measures like social distancing, wearing personal protective equipment like a mask, hand-wash, regular sanitizing, regional lockdown, closing the mass gathering places like schools, colleges, industries, pilgrim centre, shopping malls, tourist spots and other non-essential business (Zhang et al. 2020). In India, the COVID-19 has affected over 70,000 people and killed 2,200 people, subsequently, the infected persons usually experience mild to moderate respiratory issues. The Ministry of Health and Family Welfare, Government of India has stated that many older people affected with COVID-19 and other multiple health illness like cardiovascular disease, chronic respiration problem, diabetes, and cancer are most likely to build up serious illness and fatality.

The novel COVID -19 inception in late December 2019 has reduced the anthropogenic activities raised by the humans like vehicular transport, industrial emissions, fossil fuel burning and energy consumption. The pollutants such as carbon monoxide, black carbon, ozone, particulate matters, nitrous oxide and aerosols are the most common pollutants that are emitted from anthropogenic activities and which can harm human begins (Badarinath et al. 2007, Kumar et al. 2010, Ding et al. 2013, Zhang et al. 2020). The prediction of the atmospheric and climate changes can be envisaged by quantifying the primary and secondary air pollutants. Carbon monoxide (CO) is a colourless, tasteless, odourless, and non-irritating gas formed due to the incomplete or partial combustion of carbon materials (Badarinath et al. 2007). Nitrous oxide is an excellent tracer of human-induced activities, it is mostly emitted as NO from anthropogenic combustion sources like vehicular emission, power plants and residential combustion (Martin et al. 2003, Zhang et al. 2018). Aerosols are a suspension of small water droplets or solid particles carried over by the air or other gases into the atmosphere. Aerosols significantly affect the radiation and cause an imbalance between the radiation energy scattering and absorbing (Jia et al. 2019). All these pollutants are highly responsible for causing much illness to the human begins like respiratory problems, bronchitis, asthma, skin cancer and many other problems (Ghude et al. 2019). Additionally, the above-mentioned gases are an important commodity in the greenhouse gases, which are responsible for global climate change. Hence, it is necessary to understand the air quality 
trends before and after the COVID-19 situation over the Indian Sub-continent. In the present study, the spatial-temporal variation of the gaseous pollutants like carbon monoxide (CO), and Nitrogen dioxide $\left(\mathrm{NO}_{2}\right)$, using the satellite data over the Indian subcontinent were simulated and the trend of Ultraviolet Aerosol index (UVAI) was analysed before and after the novel COVID-19 pandemic situation.

\section{MATERIALS AND METHODS}

\section{Study Area}

Most of the megacities around the world are affected by air pollution and pressing a growing concern on human health. The study focused on the Indian subcontinent as many reports are suggesting the quality of urban air pollution and its related problems. The trends of the air pollution levels over the Indian subcontinent before and after the COVID-19 pandemic are analysed using satellite images. The Indian cities are grouped into six different zones which consist of many mega cities - The northern zone consists of 29 cities; Southern zone consists of 26 cities; Eastern zone consists of 21 cities; Western zone consists of 33 cities; Central zone consists of 8 cities; North-east zone consists of 11 cities. Data criterion was collected from the satellite images (https://giovanni.gsfc.nasa.gov/giovanni/) for the year 2019 and 2020 i.e., one year before the COVID-19 and during the pandemic situation.

\section{Satellite Datasets for Gaseous Air Pollutants}

GIOVANNI is an open broad web interface that allows the users to view and analyze NASA's gridded data from various satellites and surface observations. Giovanni provides the users with the data's pertaining to the atmospheric chemistry, atmospheric temperature, water vapour, atmospheric aerosols, hydrology, ocean chlorophyll, and surface temperature and analytical functions were performed by Grid Analysis and Display Systems (GrADS) (Acker \& Leptoukh 2007). The Atmospheric Infrared Sounder (AIRS) is a grating spectrometer aboard the second earth observing system (EOS) and the polar orbiting platform. AIRS comprises of an innovative atmospheric sound group with infrared, visible and microwave sound sensors with a combination of Advanced Microwave Sounding Unit (AMSU) and Humidity Sounder for Brazil (HSB). The carbon monoxide (CO) map was prepared by considering the monthly averaged mean mole fraction values in air and measured in ppbv during the ascending day time at $1 \times 1$ degree grid cells at $925 \mathrm{hPa}(\mathrm{Kahn}$ et al. 2014). The Nitrogen dioxide $\left(\mathrm{NO}_{2}\right)$ satellite data sets were acquired from the time average OMI-AURA (Ozone Monitoring Instrument-AURA) tropospheric column level 3 daily gridded at $0.25 \times 0.25$ degree resolution and measured with a unit 1 per sq. cm (Nickolay et al. 2019).

The UV aerosol index (AI) map was obtained from the daily time-weighted average from Ozone Monitoring Instrument $(\mathrm{OMI})$ at $1 \times 1$ degree resolution. The index detects the particulate maters mostly dust and soot emissions from the anthropogenic activities. It is based on the spectral contrast method in a UV region where the ozone is very minimal. The AI is the difference between the observations and model values of absorbing and non-absorbing spectral radiance ratios and given by the below equation (1),

$A I=100\left[\log _{10}\left(I_{360} / I_{331}\right)_{\text {measured }}-\log _{10}\left(I_{360} / I_{331}\right)_{\text {calculated }}\right] \ldots$ (1)

Where, $\left(\mathrm{I}_{360} / \mathrm{I}_{331}\right)_{\text {measured }}$ are the radiances measured at $360 \mathrm{~nm}$ and $331 \mathrm{~nm}$ and $\left(\mathrm{I}_{360} / \mathrm{I}_{331}\right)_{\text {calculated }}$ are the calculated radiances at $360 \mathrm{~nm}$ and $331 \mathrm{~nm}$ assuming a Rayleigh scattering atmosphere. Positive values of the Aerosol Index generally represent absorbing aerosols (dust and smoke) while small or negative values represent non-absorbing aerosols and clouds (Pawan \& Bhartia 2012).

\section{RESULTS AND DISCUSSION}

\section{Carbon Monoxide (CO)}

Spatial-temporal variation: Carbon monoxide (CO) is produced by the incomplete combustion of various carbon fuels of both biomass and fossil origins as well as from the oxidation of methane and other hydrocarbons. $\mathrm{CO}$ is a poisonous, odourless, and colourless gas. $\mathrm{CO}$ is not a direct greenhouse gas; however, $\mathrm{CO}$ and other pollutants can affect tropospheric ozone, carbon dioxide, and methane. Thus, CO can have an indirect effect on climate. The mixing ratio of $\mathrm{CO}$ is widely used as a tracer of polluted air in remote regions mainly due to its specific emission sources and longer atmospheric lifetimes of about 2 months (Sahu et al. 2019, Tang et al. 2019). CO is measured by the total column measurement; it is the number of molecules of $\mathrm{CO}$ in an atmospheric column from the Earth's surface to the top of the stratosphere above a square centimetre of the surface, it is the volume mixing ratio in parts per billion (ppbv). In South Asia, the major sources of $\mathrm{CO}$ emissions are biomass burning and anthropogenic activities including the usage of fossil fuels (Shindell et al. 2006). Yoon \& Pozzer (2014) estimated a rapid increase in $\mathrm{CO}$ mixing ratios over South Asia due to the increasing anthropogenic emissions by combining observations with a global climate model. In urban and polluted regions, the oxidation of $\mathrm{CO}$ can lead to the formation of ozone $\left(\mathrm{O}_{3}\right)$ in the presence of oxides of nitrogen (NOx $=\mathrm{NO}+\mathrm{NO}_{2}$ ) and sunlight. Additionally, $\mathrm{CO}$ is a criterion pollutant as exposure to its elevated levels adversely affects the regional to global air quality and human health (Prockop 


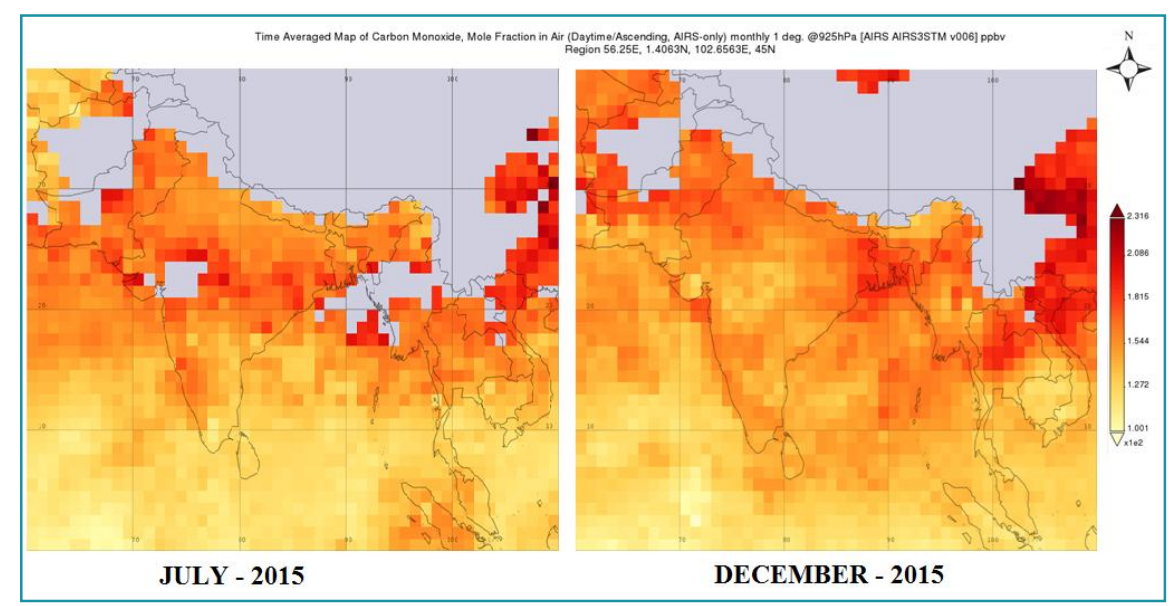

Fig. 1: Spatio-temporal variation of CO during July and December 2015.

$\&$ Chichkova 2007). Therefore, it is important to investigate the spatio-temporal variations of $\mathrm{CO}$ and the contribution of various emission sources, especially over the South Asia region where anthropogenic activities are increasing rapidly.

During July, the CO concentrations in the Indian peninsular region are much lesser in the range of $7.9-14.9 \times$ $10^{-1}$ ppbv (Fig. 1). Whereas, the concentrations of CO during the December month were over the Indian subcontinent were in the range of $10.6-18.1 \times 10^{-1} \mathrm{ppbv}$ (Fig.1). The spatio-temporal variability of $\mathrm{CO}$ in the troposphere depends on the source locations and the mixing/transport associated with the horizontal and vertical winds (Chandra et al. 2016). In the lower troposphere, the strength of local emission, dilution due to horizontal winds and vertical ventilation due to convection control the seasonal variations of primary pollutants such as $\mathrm{CO}$. In contrast, the seasonality of $\mathrm{CO}$ aloft strongly depends on the vertical transport near the ground to the middle and upper troposphere, especially in the tropics favoured by strong convection activities (Sheel et al. 2014). The near-surface wind speeds in July are higher compared to December, leading to dilution effect and hence lower CO concentration in July than in December. The spatial variation of $\mathrm{CO}$ is visible from the figure, as it is lesser in the oceans and more in the overland. The above scenario explains to us that as the anthropogenic activities (Burning of fossil fuel) are more in the land surface than in the ocean; hence concentrations of $\mathrm{CO}$ are higher in land. It was also evident from the figure that the spatial variation of $\mathrm{CO}$ over the Bay of Bengal was much higher compared to the Arabian Sea. The above scenario explains the fact that proximity of land directly affects CO levels. The Bay of Bengal is in between two landmasses and is more vulnerable to the continental wind-driven outflow of pollutants into the oceans.

Effect of COVID-19 on carbon monoxide levels: The lockdown scenario due to COVID-19 has shut many of the industries and transportation paved a negative impact on the

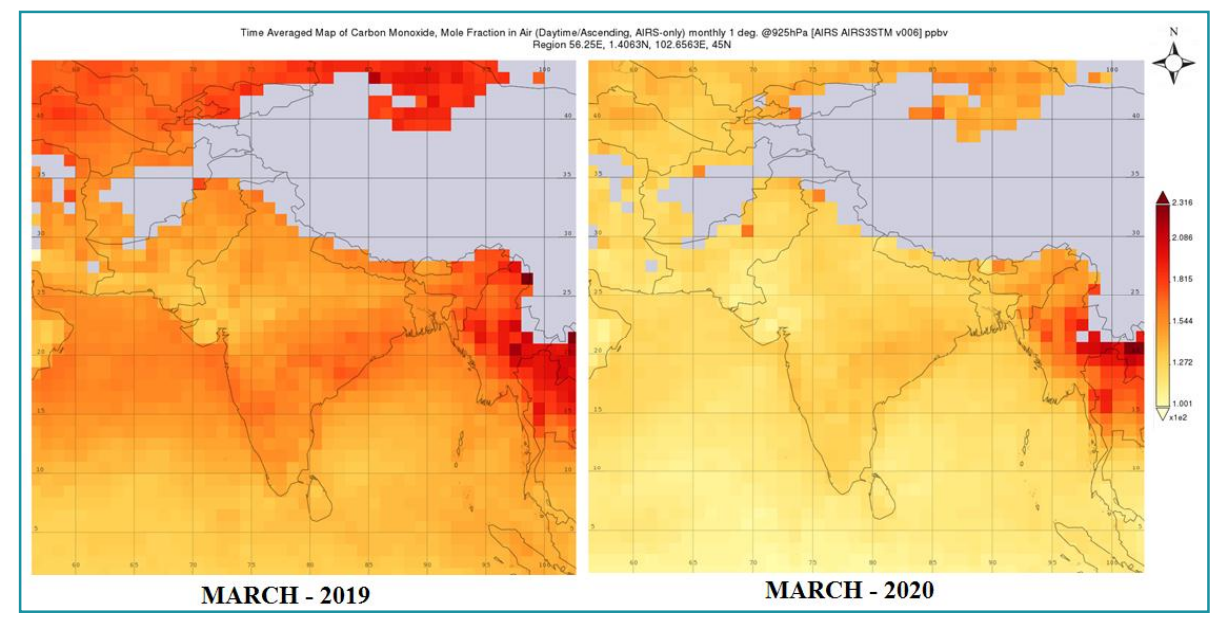

Fig. 2: Spatio-temporal variation of CO over Indian Subcontinent during March. 
economy of the country. But, there is positivity from the COVID-19, the atmospheric pollution levels have drastically come down. It was seen from the carbon monoxides levels in the air during the ascending day time at $925 \mathrm{hPa}$ (Fig. 2). During March 2019 the Indian subcontinent has emitted a carbon monoxide value ranging from $15.14-18.15 \times 10^{-1}$ ppbv while the levels of carbon monoxide came down to $1-1.27 \times 10^{-1}$ ppbv during the lockdown period. A similar trend was observed for the carbon dioxide values over the city of Kolkata (Mitra et al. 2020).

\section{Nitrogen dioxide $\left(\mathrm{NO}_{2}\right)$}

The emissions of nitrogen dioxide $\left(\mathrm{NO}_{2}\right)$ are mainly from mobile and stationary fuel combustion sources. It is an irritant gas, which can cause inflammation of the airways at a higher concentration. As the fuel gets combusted, the nitrogen present in that combine with the oxygen molecules to create nitric oxide (NO), which further reacts with nascent oxygen to form the $\mathrm{NO}_{2}$. Both these compounds are together considered as oxides of nitrogen $\left(\mathrm{NO}_{\mathrm{x}}\right)$, where $\mathrm{NO}$ are not that harmful like $\mathrm{NO}_{2}$ The $\mathrm{NO}_{\mathrm{x}}$ gases react to form smog and acid rain which can cause adverse health effects like lung diseases, respiratory problems and skin allergies, further higher concentration of nitrous oxides may damage the vegetation, leaf damages and yield (Haris et al. 2011, Deng et al. 2018, Marescaux et al. 2018).

Similar to carbon monoxide values over the Indian subcontinent, the concentrations of nitrogen dioxide have decreased due to the lockdown (Fig. 3 and 4). As it can be visualized from Fig. 4 satellite images that there were many red-orange colour pockets during March 2019, but that was significantly reduced during the 2020 period. In the same way, the May concentrations of $\mathrm{NO}_{2}$ have reduced due to lesser mobile emissions. Also, it can be visualized that over the $20-25^{\circ} \mathrm{N}$ and $80-85^{\circ} \mathrm{E}$ there were many red pouches (highlighted by encircling). The concentrations over that regions were in the range of $1.24-1.65 \times 10^{-16}$ OMI per sq. $\mathrm{cm}$ (Fig. 4). The reason may be due to may stationary emissions i.e., power plants are operational over Chhattisgarh and were in good agreement with Patra (2017).

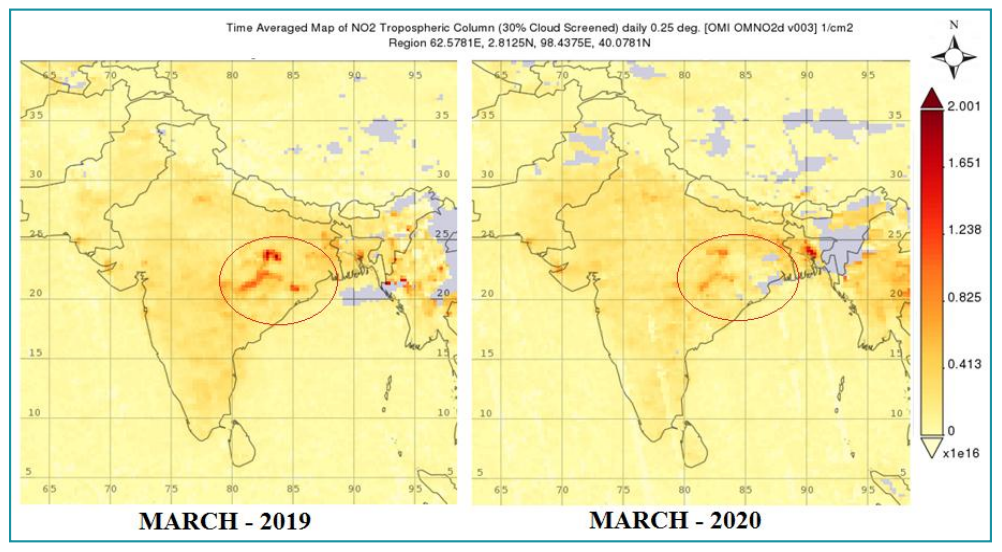

Fig. 3: Spatio-temporal variation of $\mathrm{NO}_{2}$ over Indian Subcontinent during March.

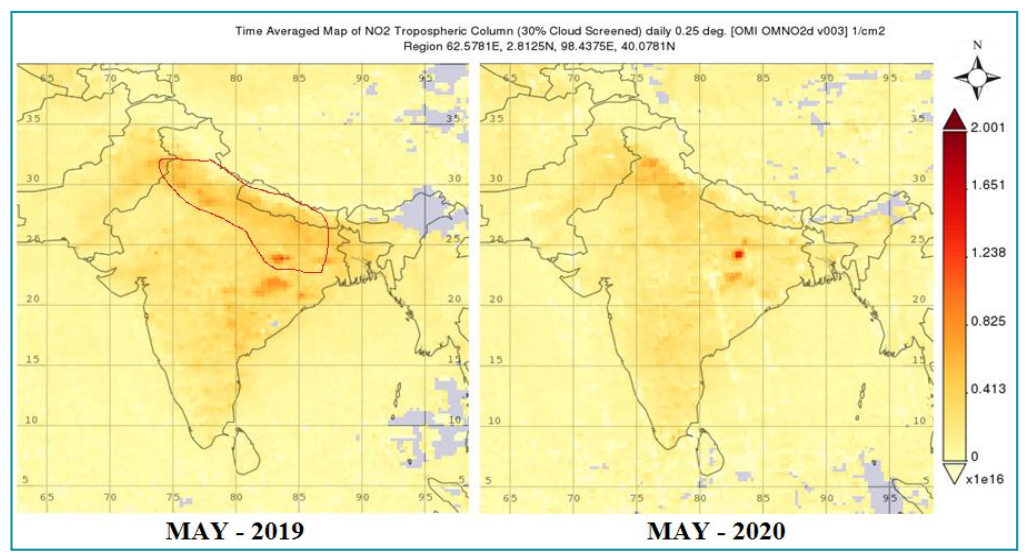

Fig. 4: Spatio-temporal variation of $\mathrm{NO}_{2}$ over Indian Subcontinent during May. 


\section{UV Aerosol Index}

The UV aerosol index (UVAI) is the vital method that detects the absorbing aerosol from the satellite near to UV wavelength range. It was explained by researchers that if a positive UVAI value was recorded, it implies that aerosol absorption is happening; a negative value indicates a non-absorbing aerosol. If the AI is close to zero, it indicates the minimal aerosol absorption or non-aerosol related effects such as clouds, ocean colour effects or sun glint (Hammer et al. 2015). The mean OMI UVAI observations for April and May 2019 and 2020 were shown in Fig. 5 and 6. It was visible that clear signals over many Indian cities during April and May 2019.

The UVAI in many of the northern cities like Noida, Delhi, Kanpur and Punjab regions were above 1.5 and 3.0. It resembles that the regions dominant in the mineral dust and biomass burning, and were in good agreement with Kumar \& Kumar (2017). After the COVID-19 lockdown situation, the UVAI has significantly reduced in many of the Indian cities as seen in the figure. The places that recorded maximum UVAI during April and May 2019 has shown decline values of UVAI (highlighted with red rounds in figures) during the same month in 2020.

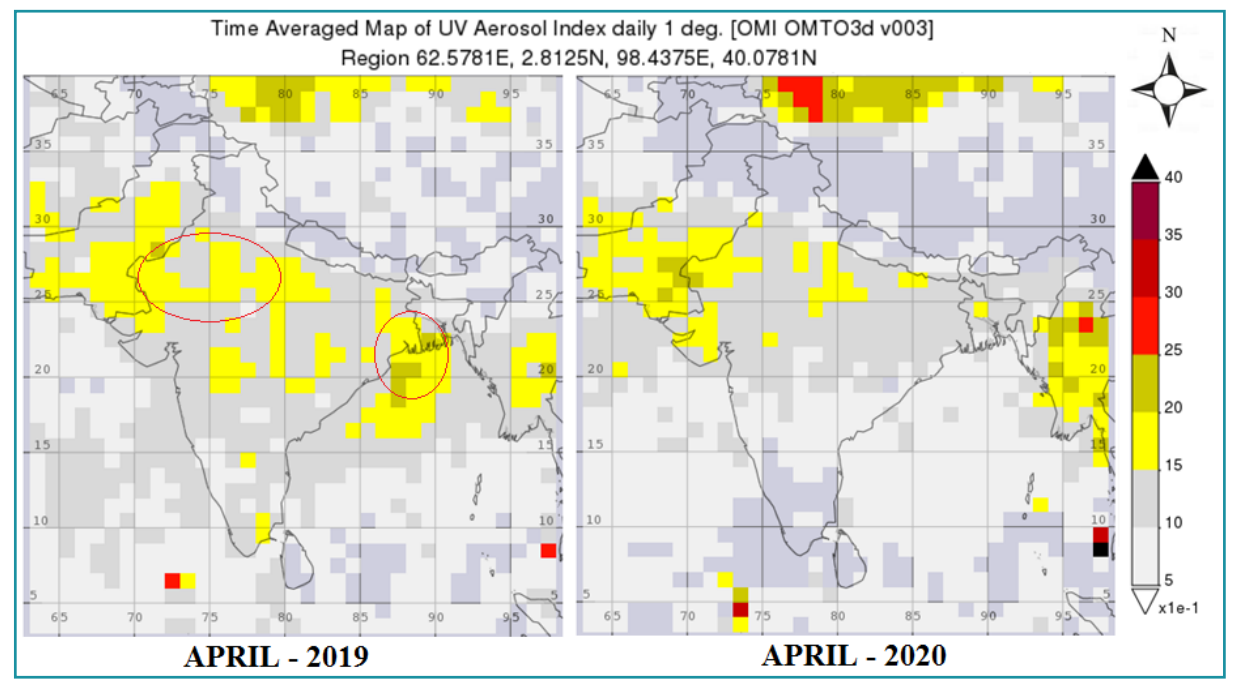

Fig. 5: Spatio-temporal variation of Aerosol Index over Indian Subcontinent during April.

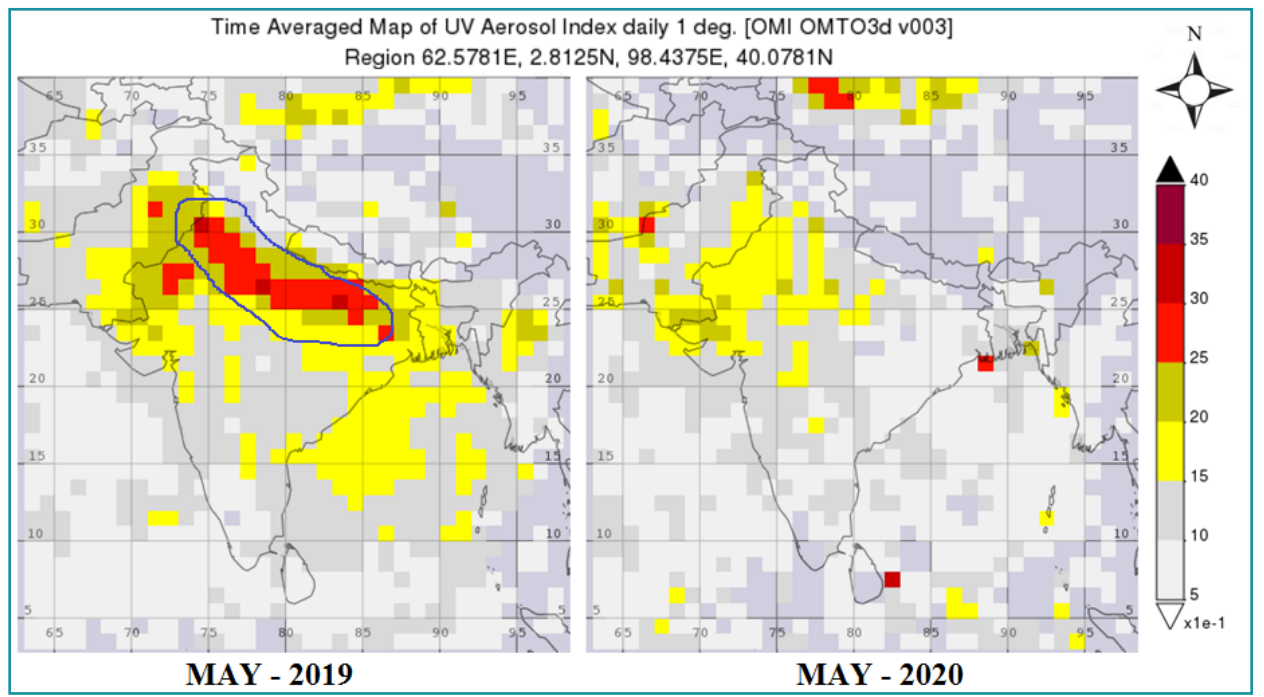

Fig. 6: Spatio-temporal variation of Aerosol Index over Indian Subcontinent during May. 


\section{CONCLUSION}

The extent of change in the atmospheric parameters like carbon monoxide $(\mathrm{CO})$, nitrogen dioxide $\left(\mathrm{NO}_{2}\right)$ and ultraviolet aerosol index (UVAI) are studied over the Indian subcontinent during the unprecedented worldwide COVID-19 pandemic scenario. The global pandemic and subsequent lockdown have flattened the world economy but it reduced the anthropogenic emission sources to a great extent. A significant reduction of primary pollutants, like $\mathrm{NO}_{2}(\sim 65 \%)$ and $\mathrm{CO}(\sim 7 \%)$ reveals that the reduced emissions from the vehicular movements and other essential anthropogenic activities, and reveals a better air quality during the lockdown. There was more than a 57\% reduction in the UV aerosol index (UVAI) as the value was 1.5-3.5 during the year May 2019 and reduced to 0.5-2.0 during the year May 2020. The above results are evident that apart from the local meteorological and natural emissions like sea spray and pollen grains, the lockdown of various industries, lesser vehicular emissions have decreased the dust as well as smoke emissions thereby the reduced UVAI values. Amongst the three atmospheric pollutants studied, $\mathrm{CO}$ was the least impacted by the lockdown. The emissions of $\mathrm{CO}$ were predominantly from fossil fuel burning, and the least contribution was seen during the lockdown as well as $\mathrm{CO}$ has a longer atmospheric lifetime. Hence, the novel COVID-19 has many negative impacts worldwide but showed few positive effects on the environment by reducing the atmospheric pollutants level and provided a unique opportunity for the researchers to explore sustainable and balanced mitigation strategies.

\section{REFERENCES}

Acker, J. G. and Leptoukh, G. 2007. Online analysis enhances use of NASA earth science data. Eos. Trans. AGU., 88(2): 14-17.

Badarinath, K. V. S., Kharol, S. K., Chand, T. K., Parvathi, Y. G., Anasuya, T. and Jyothsna, A. N. 2007. Variations in black carbon aerosol, carbon monoxide and ozone over an urban area of Hyderabad, India, during the forest fire season. Atmos. Res., 85(1): 18-26.

Chandra, N., Venkataramani, S., Lal, S., Sheel, V. and Pozzer, A. 2016. Effects of convection and long-range transport on the distribution of carbon monoxide in the troposphere over India. Atmos. Pollut. Res., 7(5): 775-785.

Deng, J., Guo, L., Salas, W., Ingraham, P., Charrier-Klobas, J. G., Frolking, S. and $\mathrm{Li}, \mathrm{C}$. 2018. Changes in irrigation practices likely mitigate nitrous oxide emissions from California cropland. Global Biogeochem. Cycles, 32(10): 1514-1527.

Ding, A., Wang, T. and Fu, C. 2013. Transport characteristics and origins of carbon monoxide and ozone in Hong Kong, South China. J. Geophys. Res. D: Atmos., 118(16): 9475-9488.

Ghude, S. D., Karumuri, R. K., Jena, C., Kulkarni, R., Pfister, G. G., Sajjan, V. and Kulkarni, S. H. 2019. What is driving the diurnal variation in tropospheric $\mathrm{NO}_{2}$ columns over a cluster of high emission thermal power plants in India? Atmos. Environ., X: 100058.

Hammer, M. S., Martin, R. V., van Donkelaar, A., Buchard, V., Torres, O., Ridley, D. A. and Spurr, R. J. 2015. Interpreting the Ultraviolet Aerosol Index observed with the OMI satellite instrument to understand absorption by organic aerosols: implications for atmospheric oxidation and direct radiative effects. Atmos. Chem. Phys. Discuss., 15(19).

Haris, A. A., Pragyan, K., Vandna, C. and Sandeep, B. 2011. Modeling the impact of anticipated climate change on wheat yields in two different agro-climatic zones of eastern India. J. Agrometeorol., 13(2): 116-118.

Jia, R., Luo, M., Liu, Y., Zhu, Q., Hua, S., Wu, C. and Shao, T. 2019. Anthropogenic aerosol pollution over the eastern slope of the Tibetan Plateau. Adv. Atmos. Sci., 36(8): 847-862.

Kahn, B. H., Irion, F. W., Dang, V. T., Manning, E. M., Nasiri, S. L., Naud, C. M. and Fetzer, E. J. 2014. The atmospheric infrared sounder version 6 cloud products. Atmospheric Chemistry and Physics, 14(1): 399-426.

Kumar, R., Sharma, S. K., Thakur, J. S., Lakshmi, P. V. M., Sharma, M. K. and Singh, T. 2010. Association of air pollution and mortality in the Ludhiana city of India: a time-series study. Indian J. Public Health, 54(2): 98.

Kumar, S. and Kumar, S. 2017. Impact of aerosol on climate and productivity of rice and wheat crop in Bihar. J.Agrometeorol., 19(1): 23.

Marescaux, A., Thieu, V. and Garnier, J. 2018. Carbon dioxide, methane and nitrous oxide emissions from the human-impacted Seine watershed in France. Sci. Total Environ., 643: 247-259.

Martin, R. V., Jacob, D. J., Chance, K., Kurosu, T. P., Palmer, P. I. and Evans, M. J. 2003. Global inventory of nitrogen oxide emissions constrained by spacelbased observations of $\mathrm{NO}_{2}$ columns. J. Geophys. Res. D: Atmos., 108(D17).

Mitra, A., Chaudhuri, T. R., Mitra, A., Pramanick, P., Zaman, S., Mitra, A. and Zaman, S. 2020. Impact of COVID-19 related shutdown on atmospheric carbon dioxide level in the city of Kolkata. Sci. Edu., 6(3): 84-92.

Nickolay, A., Krotkov, Lok N. Lamsal, Sergey, V. Marchenko, Edward A. Celarier, Eric J. Bucsela, William, H. Swartz, Joanna Joiner and the OMI core team. 2019. OMI/Aura $\mathrm{NO}_{2}$ Cloud-Screened Total and Tropospheric Column L3 Global Gridded 0.25 degree x 0.25 degree V3, NASA Goddard Space Flight Center, Goddard Earth Sciences Data and Information Services Center (GES DISC), (Accessed on May 13, 2020), 10.5067/Aura/OMI/DATA3007

Patra, A. K. 2017. Accounting methane and nitrous oxide emissions, and carbon footprints of livestock food products in different states of India. J. Cleaner Prod., 162: 678-686.

Pawan, K. and Bhartia 2012. OMI/Aura TOMS-Like Ozone, Aerosol Index, Cloud Radiance Fraction L3 1 day 1 degree x 1 degree V3, NASA Goddard Space Flight Center, Goddard Earth Sciences Data and Information Services Center (GES DISC), (Accessed on May 13, 2020), 10.5067/Aura/OMI/DATA3001

Prockop, L. D. and Chichkova, R. I. 2007. Carbon monoxide intoxication: an updated review. J. Neurol.Sci., 262(1-2): 122-130.

Sahu, L. K., Tripathi, N., Sheel, V. and Ojha, N. 2019. The influence of local meteorology and convection on carbon monoxide distribution over Chennai. J. Earth Syst. Sci., 128(5): 119.

Sheel, V., Sahu, L. K., Kajino, M., Deushi, M., Stein, O. and Nedelec, P. 2014. Seasonal and interannual variability of carbon monoxide based on MOZAIC observations, MACC reanalysis, and model simulations over an urban site in India. J. Geophys. Res. D: Atmos., 119(14): 9123-9141.

Shindell, D. T., Faluvegi, G., Stevenson, D. S., Krol, M. C., Emmons, L. K., Lamarque, J. F. and Wild, O. 2006. Multimodel simulations of carbon monoxide: Comparison with observations and projected nearfuture changes. J. Geophys. Res. D: Atmos., 111(D19).

Tang, W., Emmons, L. K., Arellano Jr, A. F., Gaubert, B., Knote, C., Tilmes, S. and Blake, N. J. 2019. Source contributions to carbon monoxide concentrations during KORUS-AQ based on CAM-chem model applications. J. Geophys. Res. D: Atmos., 124(5): 2796-2822. 
WHO, World Health Organization. Coronavirus Disease (COVID-19) Pandemic. Available online: https: //www.who.int/emergencies/ diseases/novel-coronavirus-2019 (accessed on 5 May 2020).

Yoon, J. and Pozzer, A. 2014. Model-simulated trend of surface carbon monoxide for the 2001-2010 decade. Atmos. Chem. Phys., 10465.

Zhang, R., Wang, Y., Smeltzer, C., Qu, H., Koshak, W. and Boersma, K.
F. 2018. Comparing OMI-based and EPA AQS in situ NO2 trends: towards understanding surface NOx emission changes. Atmos. Meas. Tech., 11(7): 3955-3967.

Zhang, R., Zhang, Y., Lin, H., Feng, X., Fu, T. M. and Wang, Y. 2020. NOx emission reduction and recovery during COVID-19 in East China. Atmos., 11(4): 433. 